\title{
One-Step Immunochromatography Assay for Detection of High-Level Canine Serum Trypsin-Like Immunoreactivity
}

\author{
Takaki WARITANI ${ }^{1)}$, Masaaki ONDA ${ }^{1)}$, Yoko OKUNO ${ }^{1)}$, Sakurako NEO ${ }^{2}$, Mitsuru FURUICHI ${ }^{2}$, Masaharu HISASUE ${ }^{2)}$, \\ Ryo TSUCHIYA ${ }^{2)}$ and Takatsugu YAMADA ${ }^{2) *}$ \\ 1) Animal Health Products and Chemicals Division, Animal Health Products and Chemicals Research Section, Daiichi Fine Chemical Co., \\ Ltd., 530 Chokeiji, Takaoka-shi, Toyama 933-8511 and ${ }^{2}$ Laboratory of Veterinary Internal Medicine, School of Veterinary Medicine, \\ Azabu University, 1-17-71 Fuchinobe, Sagamihara-shi, Kanagawa 229-8501, Japan
}

(Received 17 April 2006/Accepted 22 February 2007)

ABSTRACT. We developed a one-step immunochromatography assay kit to measure high levels of canine trypsin-like immunoreactivity (cTLI) for bedside estimation of canine pancreatitis. The serum cTLI level can be determined within 10 min by visual comparison of color strengths in the test and reference zones. The serum cTLI levels determined by this method correlate well with canine TLI-ELISA and can be classified into 3 categories: cTLI levels higher than $60 \mathrm{ng} / \mathrm{ml}$ were considered positive; 20-60 $\mathrm{ng} / \mathrm{ml}$, weakly positive; and less than $20 \mathrm{ng} / \mathrm{ml}$, negative. Twelve dogs suspected of pancreatitis were examined using this method; 4 dogs were positive, 2 were weakly positive, and 6 were negative. This test can detect a high level of serum cTLI and a positive result in the TLIH test will provide critical information for evaluation of pancreatitis in dogs.

KEY WORDS: canine, pancreatitis, TLI.

The diagnosis of canine acute pancreatitis is difficult because the clinical signs are not specific and laboratory data can give unreliable results. Serum amylase and/or lipase activity are sometimes used as biochemical makers. However, these markers are not reliable for diagnosis of canine pancreatitis due to their lack of specificity to pancreatic disorders [14]. Recently, it has been reported that assays of immunoreactive pancreatic lipase $[12,13]$ and trypsinogen activation peptide [5] are useful as diagnostic markers for canine pancreatitis. However, relevant information is required quickly for treatment of pancreatitis, and the existing biochemical markers are not rapid enough for bedside diagnosis of pancreatitis because most these assay systems employ enzyme-linked immunosorbent assay (ELISA) or radioimmunoassay (RIA).

Canine trypsin-like immunoreactivity (cTLI), which includes trypsin and trypsinogen, has been reported to be a more suitable indicator of canine pancreatitis than lipase and amylase activity. Because trypsin and its precursor, trypsinogen, are synthesized and stored by acinar cells in the pancreas, trypsin is believed to be highly specific to pancreatic function without reflecting other diseases [10]. Serum cTLI levels determined by ELISA and RIA are significantly lower in dogs with exocrine pancreatic insufficiency (EPI) than in normal dogs $[17,18]$. We previously developed a simple bedside test using an immunochromatography system to determine low levels of cTLI in canine sera for diagnosis of EPI [15].

On the other hand cTLI levels are apparently high in the early phase of experimentally induced pancreatitis $[2,3,10$,

\footnotetext{
* CorRespondence to: Yamada, T., Laboratory of Veterinary Internal Medicine, School of Veterinary Medicine, Azabu University, 1-17-71 Fuchinobe, Sagamihara-shi, Kanagawa 229-8501, Japan.
}

$11,18]$. Therefore, a simple method to assay cTLI levels at bedside will be helpful for evaluate not only EPI but also pancreatitis.

In this study, we have developed a immunochromatography assay method for determining high levels of cTLI (TLIH test) that is utilizable at bedside without any special equipment. Serum cTLI from dogs suspected of pancreatitis were measured by this TLIH test.

In this test kit, 2 monoclonal antibodies that recognize independent epitopes of cTLI are used to capture serum cTLI and the cTLI-monoclonal antibody $(\mathrm{mAb})$ complex, respectively. To perform the assay, 1 drop of the sample (serum or plasma) and 3 drops of the reaction buffer $(0.05 \mathrm{M}$ PBS $[\mathrm{pH}=8.0]$ containing $0.05 \%$ Tween-20) are added to the sample well. The cTLI in the sample permeates a pad that contains immobilized anti-cTLI mAb 009-303 conjugated with colloidal gold. The conjugate forms immune complexes with the cTLI in the sample and infiltrates a nitrocellulose membrane by capillary action toward the test zone, which is coated with anti-cTLI mAb 008-207. In the test zone, the colloidal gold and the antibody-cTLI complex are captured by anti-cTLI mAb 008-207. The color density of the colloidal gold in the test zone increases in proportion to increases in cTLI levels in the serum. The excess free $\mathrm{mAb}$ 009-303 conjugated with colloidal gold, which is not captured in the test zone, continues to migrate to the reference zone, in which biotinylated-cTLI is immobilized by an avidin coating on the membrane surface. In the reference zone, free mAb 009-303-conjugated colloidal gold binds to the biotinylated cTLI (Fig. 1). When the cTLI concentration in the sample is high, mAb 009-303-conjugated colloidal gold is bound with the plentiful cTLI in the sample. The cTLI and mAb 009-303 immune complexes migrate to the test zone and bind to mAb 008-207 at the maximum level 


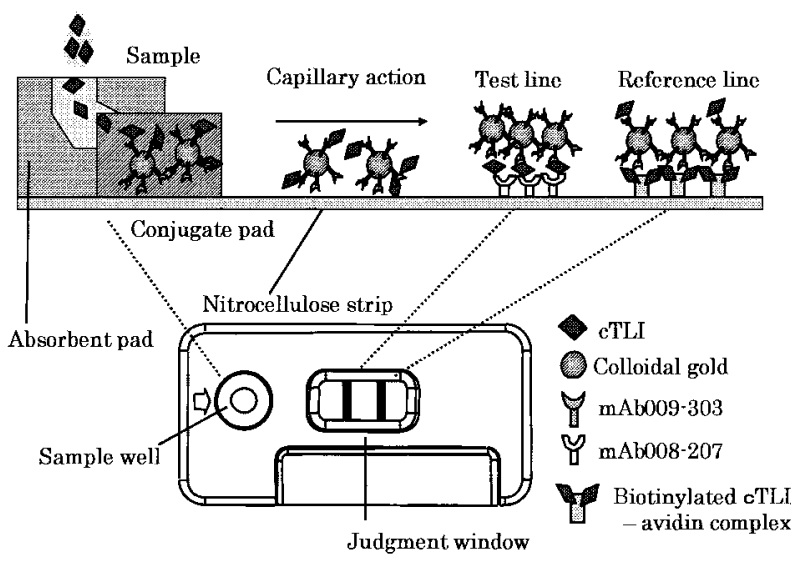

Fig. 1. Composition and mechanism of the TLIH test. The precise mechanism is described in the text. The kit is composed of a sample well (absorbent pad), conjugation pad, test zone, and reference zone. These four parts are connected by a nitrocellulose strip. Anti-cTLI mAb 009-303 conjugated with colloidal gold is immobilized on the conjugation pad. In the test zone (test line), a nitrocellulose strip is coated with anti-cTLI mAb 008-207. In the reference zone (reference line), biotinylated cTLI is immobilized by avidin to a nitrocellulose strip.

(appearing as a strong red line). However, some of the free $\mathrm{mAb}$ 009-303 reaches the reference zone and binds to the biotinylated cTLI fixed there. In that case, the color of the reference line is weaker than the test line. As a result of the competition for $\mathrm{mAb} 009-303$ between cTLI in the sample and biotinylated cTLI, the color density in the reference zone increases in inverse proportion to the cTLI levels in the sample.

In this system, a red line appears in the test and reference zones within $10 \mathrm{~min}$. When a cTLI solution of known concentration was used, samples were classified into three cate-
Table 1. Precision and accuracy of the immunochromatography assy test

\begin{tabular}{|c|c|c|c|}
\hline \multirow{2}{*}{$\begin{array}{l}\text { TLI concentration } \\
\text { by ELISA }\end{array}$} & \multicolumn{3}{|c|}{ Result of TLIH tes } \\
\hline & $1 \mathrm{st}$ & 2nd & $3 \mathrm{rd}$ \\
\hline 195.9 & + & + & + \\
\hline 191.1 & + & + & + \\
\hline 163.6 & + & + & + \\
\hline 139.7 & + & + & + \\
\hline 137.7 & + & + & + \\
\hline 108.3 & + & + & + \\
\hline 104.5 & + & + & + \\
\hline 87.3 & + & + & + \\
\hline 76.7 & + & + & + \\
\hline 72.2 & + & \pm & + \\
\hline 62.8 & \pm & + & \pm \\
\hline 53.6 & \pm & \pm & \pm \\
\hline 49.7 & \pm & \pm & \pm \\
\hline 47.8 & \pm & \pm & \pm \\
\hline 45.5 & \pm & \pm & \pm \\
\hline 32.8 & \pm & \pm & \pm \\
\hline 31.9 & \pm & \pm & - \\
\hline 28.1 & \pm & \pm & \pm \\
\hline 27.7 & \pm & \pm & \pm \\
\hline 22.6 & \pm & \pm & \pm \\
\hline 19.6 & \pm & - & \pm \\
\hline 18.3 & - & \pm & - \\
\hline 17.8 & - & - & - \\
\hline 12.6 & - & - & - \\
\hline 11.8 & - & - & - \\
\hline 11.1 & - & - & - \\
\hline 10.8 & - & - & - \\
\hline 6.7 & - & - & - \\
\hline 6.5 & - & - & - \\
\hline 5.9 & - & - & - \\
\hline
\end{tabular}

TLI: Trypsin-like immunoreactivity, +: Positive, \pm : Week positive, -: Negative. ELISA and immunochromatography assay test results, which were performed three times on each sample, were compared.

Table 2. Clinical details of dogs suspected pancreatitis

\begin{tabular}{|c|c|c|c|c|c|c|c|c|c|c|c|c|}
\hline $\begin{array}{l}\text { Sample } \\
\text { number }\end{array}$ & Breed & Age & Sex & $\begin{array}{l}\text { Lipase } \\
\text { (IU/L) }\end{array}$ & $\begin{array}{c}\text { Amylase } \\
\text { (IU/L) }\end{array}$ & $\begin{array}{c}\text { ALT } \\
(\mathrm{IU} / \mathrm{L})\end{array}$ & $\begin{array}{c}\text { ALP } \\
(\mathrm{IU} / \mathrm{L})\end{array}$ & $\begin{array}{c}\text { BUN } \\
(\mathrm{mg} / \mathrm{dL})\end{array}$ & $\begin{array}{c}\text { Creatinine } \\
(\mathrm{mg} / \mathrm{dL})\end{array}$ & $\begin{array}{l}\text { Suspected } \\
\text { disease }\end{array}$ & $\begin{array}{c}\text { cTLI } \\
(n \mathrm{~g} / \mathrm{mL})\end{array}$ & $\begin{array}{l}\text { Result of } \\
\text { TLIH test }\end{array}$ \\
\hline & Reference ranges & & & $0-800$ & $0-3000$ & $0-100$ & $0-200$ & $10-25$ & $0.5-1.2$ & & $7.8-29.2$ & \\
\hline 1 & Mongrel & $4 \mathrm{M}$ & ১ & ND & ND & 252 & 585 & 21.4 & 0.5 & AP & 28.4 & \pm \\
\hline 2 & Chihuahua & $4 \mathrm{Y}$ & $\sigma^{\top}$ & ND & ND & 67 & 32 & 23.7 & 0.5 & AP & 73.8 & + \\
\hline 3 & Poodle & $13 \mathrm{Y}$ & $\sigma^{\top}$ & 1066 & 274 & 20 & 1125 & 5.4 & 1.0 & $\mathrm{CP}$ & 1.0 & - \\
\hline 4 & Old English sheepdog & $2 \mathrm{Y} 8 \mathrm{M}$ & 우 & 1149 & 2102 & 31 & 160 & 4.8 & 1.1 & UD & 17.2 & - \\
\hline 5 & Pomeranian & $3 \mathrm{Y} 7 \mathrm{M}$ & $0^{\top}$ & 2257 & 13715 & 62 & 146 & 26.5 & 0.8 & AP & 287.4 & + \\
\hline 6 & Shiba & $10 \mathrm{Y}$ & $\times 0^{7}$ & 1105 & 1012 & 46 & 46 & 11.9 & 0.6 & $\mathrm{CP}$ & 4.1 & - \\
\hline 7 & Mongrel & $11 \mathrm{Y}$ & 우 & ND & ND & 20 & 54 & 17.1 & 0.8 & $\mathrm{CP}$ & 88.2 & + \\
\hline 8 & Welsh corgi & $1 \mathrm{Y} 2 \mathrm{M}$ & 우 & 20 & 476 & 151 & 143 & 10.8 & 0.7 & $\mathrm{CP}$ & 0.0 & - \\
\hline 9 & Maltese & $12 \mathrm{Y}$ & $\sigma^{7}$ & 200 & 1914 & 85 & 93 & 41.0 & 0.4 & UD & 128.0 & + \\
\hline 10 & Shiba & $5 \mathrm{Y}$ & $\times 0^{7}$ & 120 & 1715 & 45 & 70 & 15.0 & 1.0 & UD & 9.0 & - \\
\hline 11 & Terrier & $1 \mathrm{Y} 10 \mathrm{M}$ & 우 & 266 & 2361 & 14 & 28 & 32.4 & 1.3 & $\mathrm{CP}$ & 22.7 & \pm \\
\hline 12 & Welsh corgi & $1 \mathrm{Y}$ & 우 & 434 & 517 & 840 & 1790 & 16.0 & 1.2 & UD & 14.2 & - \\
\hline
\end{tabular}

ND: Not detamined, $\sigma^{7}:$ Male, $\times \delta^{7}:$ Castrated male, 우: Female, ALT:Alanine aminotransferase, ALP: Alkaline phosphatase, BUN: Blood urea nitrogen, cTLI: Canine trypsin-like immunoreactivity, AP: Suspected acute pancreatitis, CP: Suspected chronic pancreatitis, UD: Undifferentiated. Result from TLIH test; +: Positive, \pm : Weakly positive, -: Negative. Reference ranges were determined with COBAS INTEGRA 700 (Roche Diagnostics, Switzerland). Reference range of cTLI was determined by ELISA for canine TLI. 
gories depending on the concentration of cTLI. When the cTLI concentration is higher than $60 \mathrm{ng} / \mathrm{ml}$, the red color of test line is deeper than the reference line and the result is judged to be positive. On the other hand, when the cTLI level is less than $20 \mathrm{ng} / \mathrm{ml}$, the red of the reference line is deeper than the test line and the result is judged to be negative. When the cTLI level is in the range of 20 to $60 \mathrm{ng} / \mathrm{ml}$, the color density of the sample and reference lines are equivalent and the result is judged to be weakly positive (Table 1).

In this study, cTLI levels of canine sera were classified by TLIH test kit and measured by canine TLI-ELISA. Sera were collected from patient dogs at the Veterinary Teaching Hospital of Azabu University and clinically healthy dogs kept in the Biosciences Research Institute of Azabu University (Table 2). The patient dogs were diagnosed by their clinical history, physical examination, serum chemistry profile, and various combinations of ancillary tests. In some cases, abdominal radiography, ultrasonography, and histopathology of pancreatic tissue were included. Among 100 dogs, 12 dogs were suspected of pancreatitis ( 3 acute cases, 5 chronic cases, and 4 undifferentiated cases), and 23 dogs were suspected of gastrointestinal diseases. In addition, 65 clinically healthy dogs were examined as controls (Fig. 2).

Of serum samples from 65 control dogs, the cTLI levels of 57 samples were negative and the levels of 8 samples were weakly positive (Fig. 2). The cTLI levels of control samples $(\mathrm{n}=65)$ were in the range of 7.8 to $29.2 \mathrm{ng} / \mathrm{ml}$, all cTLI levels of the weakly positive 8 samples were in the upper limit of the normal range. Among 12 dogs suspected of pancreatitis, the cTLI levels of sera from four dogs (Nos. 2, 5, 7, and 9) were positive and higher than the normal range. The cTLI levels of sera from two others were weakly positive and 22.7 and $28.4 \mathrm{ng} / \mathrm{ml}$. The levels of sera from 6 others were negative within normal limits or below normal.

In this study, the range of serum cTLI levels in the dogs unsuspected of pancreatitis were narrow, but the levels in the dogs suspected of pancreatitis ranged widely.

Several papers demonstrated that cTLI levels are apparently high in the early phase of experimentally induced pancreatitis $[2,3,10,11,18]$. It was reported that the very low cTLI values observed in chronic pancreatitis due to the inadequate pancreatic function resulting from calcification of pancreatic tissues [16]. Therefore, the pancreatic functions in the dogs suspected of pancreatitis were considered to be affected by various factors and reflect the cTLI levels. More detailed studies are required. The TLIH test can detect a high level of serum cTLI and a positive result in the TLIH test provide critical information for evaluation of pancreatitis in dogs.

\section{REFERENCES}

1. Archer, F.J., Kerr, M.E. and Houston, D.M. 1997. Zentralbl.

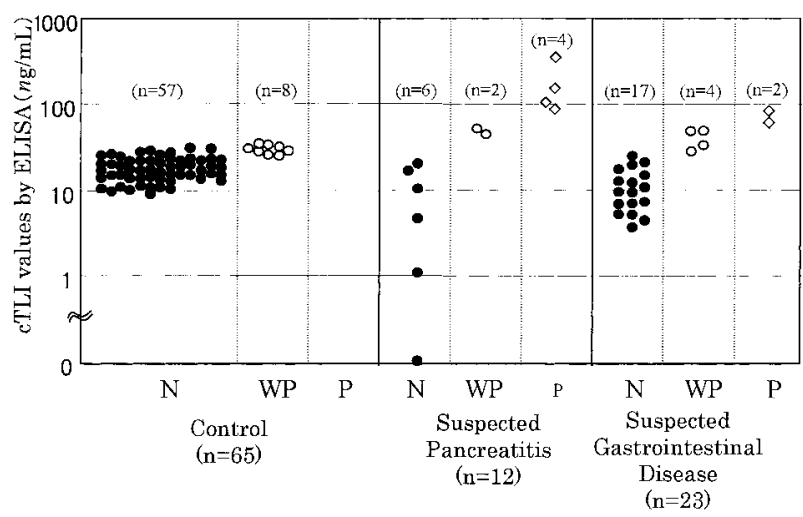

Fig. 2. Comparison of cTLI concentrations as measured by ELISA and the TLIH test in the sera of clinically healthy or diseased dogs. Sera from 65 control dogs, 12 with suspected pancreatitis, and 23 with suspected gastrointestinal disease were used. Symbols represent negative (N: ) , weakly positive (WP: $\mathrm{O})$, and positive $(\mathrm{P}: \diamond)$ results obtained by the TLIH test.

Veterinärmed. A 44: 109-13.

2. Borgstrom, A. and Ohlsson, K. 1980. Hoppe Seyler's Z. Physiol. Chem. 361: 625-631.

3. Geokas, M.C., Largman, C., Durie, P.R., Brodrick, J.W., Ray, S.B., O'Rourke, M. and Vollmer, J. 1981. Am. J. Pathol. 105: 31-39.

4. Koop, M., Rumpf, KW., Lankish, P.G., Bothe, E., Stockmann, F. and Arnold, R. 1980. Digestion 20: 334-335.

5. Mansfield, C.S. and Jones, B.R. 2000. Aust. Vet. J. 78: 416421.

6. Ohlsson, K. 1971. Acta Physiol Scand. 81: 269-272.

7. Ohlsson, K. 1971. Scand. J. Clin. Lab. Invest. 28: 219-223.

8. Ruaux, C.G. and Atwell, R.B. 1999. Res. Vet. Res. 67: 83-87.

9. Ruaux, C.G., Lee, R.P. and Atwell, R.B. 1999. Res. Vet. Res. 66: $185-190$

10. Simpson, K.W., Batt, R.M., Mclean, L. and Morton, D.B., 1989. Am. J. Vet. Res. 50: 629-632.

11. Simpson, K.W., Beechey-Newman, N., Lamb, C.R., Smyth, J.B., Hughes, G., Coombe, K., Sumar, N. and Hermon-Taylor, J. 1995. Dig. Dis. Sci. 40: 2152-2161.

12. Steiner, J.M., Broussard, J., Mansfield, C.S., Gumminger, S.R. and Williams, D.A. 2001. Am. Coll. Vet. Int. Med. 15: 274.

13. Steiner, J.M., Teague, S.R. and Williams, D.A. 2003. Can. J. Vet. Res. 67: 175-182.

14. Strombeck, D.R., Farver, T. and Kaneko, J.J. 1981. Am. J. Vet. Res. 42: 1966-1970.

15. Waritani, T., Okuno, Y., Ashida, Y., Hisasue, M., Tsuchiya, R., Kobayashi, K. and Yamada, T. 2002. Vet. Immunol. Immunopathol. 87: 41-49.

16. Watson, P.J. 2003. J. Small. Anim. Pract. 44: 306-312.

17. Williams, D.A. and Batt, R.M. 1983. J. Small Anim. Pract. 24: 583-588.

18. Williams, D.A. and Batt, R.M. 1988. J. Am. Vet. Med. Assoc. 19: 195-200. 